Disponível em

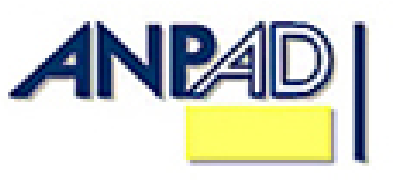

http://www.anpad.org.br/rac

RAC, Rio de Janeiro, v. 19, Edição Especial, art. 5, pp. 77-97, Maio 2015

http://dx.doi.org/10.1590/1982-7849rac20151496

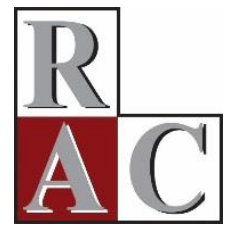

$($ (c) EY-No

\title{
Como a Gestão de Práticas de Oferta de Crédito Impacta a de Estoque
}

\author{
How Credit Extension Management affects Inventory Practices
}

Claudinê Jordão Carvalho Universidade Federal de Uberlândia - UFU

Artigo recebido em 13.06.2013. Última versão recebida em 22.08.2014. Aprovado em 24.08.2014. 


\title{
Resumo
}

O objetivo deste estudo é analisar o impacto da gestão das práticas de oferta de crédito sobre a de estoques em uma amostra de 432 micro e pequenas empresas. O modelo apoiou-se nas teorias de agência, de custos de transação e da pecking order. Os dados da amostra foram submetidos a técnicas multivariadas, de análise fatorial confirmatória e exploratória, e regressões estruturais simultâneas. A proposição de que a gestão das práticas de crédito determina a gestão de estoques, quando mediada pela gestão de caixa, foi suportada. O estudo dimensionou os reflexos dos efeitos diretos e dos indiretos entre os três construtos latentes.

Palavras-chave: oferta de crédito; gestão de caixa interno; estoques; equações estruturais.

\begin{abstract}
The aim of this paper is to analyze the impact credit extension management has on inventory management practices for a sample of 432 micro and small enterprises (MSEs). The model relied on agency, transaction cost and pecking order theories. Sample data were subjected to multivariate techniques of exploratory and confirmatory factor analysis and simultaneous structural regressions. Results support the idea that credit management practices positively determine inventory management, when mediated by cash management. The study measured direct and indirect effects among the three latent construct variables.
\end{abstract}

Key words: credit extension; internal cash management; inventories; structural equations. 


\section{Introdução}

A importância do capital de giro para o desempenho das firmas é inquestionável nos meios empresarial e acadêmico. O destaque a esse atributo ocorre em virtude de uma parte substancial do capital e da mão de obra nas MPEs estar investida em contas do ativo circulante (recebíveis, estoques e caixa). Para ter-se uma ideia da representatividade dessas decisões, no agregado, as pequenas e médias empresas (PMEs) espanholas alocavam cerca de 69\% do ativo total em itens circulantes (García-Teruel \& Martínez-Solano, 2007) e consumiam, em média, $80 \%$ do tempo dos gestores financeiros (C.-H. Chang, Dandapani, \& Prakash, 1995).

A decomposição do ativo circulante nos dá uma noção de como as firmas alocam o capital entre as contas ativas de curto prazo. A proporção média entre o investimento em caixa e o ativo total variou entre $16 \%$ e $27 \%$ em firmas norte-americanas (Bates, Kahle, \& Stulz, 2009), enquanto que a carteira de recebíveis em MPEs era de 19,18\% na Finlândia, e de 39,28\% na Espanha (García-Teruel \& MartínezSolano, 2010), bem como de cerca de 16 a $30 \%$ em estoques nas firmas industriais norte-americanas (Weston \& Brigham, 2000). Apesar de todo esse investimento, Shin e Soenen (1998) atribuíram o insucesso da rede de varejo norte-americana Kmart às práticas pobres da gestão do capital de giro institucionalizadas pelos gestores e aos altos custos financeiros decorrentes daquelas ações.

A respeito dessas ações, as evidências internacionais mostram que existem grandes diversidades e variações de formas de administração, que, por sua vez, afetam a produtividade e o desempenho das firmas e dos países (Bloom \& Van Reenen, 2010). No que concerne à gestão das práticas do capital de giro, Howorth e Westhead (2003) e Carvalho e Schiozer (2012) encontraram evidências de que os dirigentes de MPEs britânicas e brasileiras priorizam determinadas condutas em detrimento de outras. Esse comportamento revelou que os gestores podem assumir quatro estilos diferentes de gestão das rotinas inerentes ao capital de giro: (a) em estoques; (b) em caixa; (c) em crédito; e (d) outras com baixa disposição em controlar, o que está em linha com as considerações de Bloom e Van Reenen (2010).

A despeito da relevância econômica do assunto, Hill, Kelly e Highfield (2010) advertem que a análise desse tema é complexa em decorrência dos potenciais problemas de endogeneidade que podem surgir das decisões concomitantes ocorridas nas empresas, nas áreas comercial, financeira e de operações, cujos efeitos podem impactar, em sentidos opostos, os valores das contas que compõem o capital de giro operacional das firmas. Por exemplo, a decisão de ampliar a oferta de crédito pode aumentar a receita e ganhar participação de mercado, mas também amplifica os riscos tanto de perdas de vendas, por falta de estoque, como por insolvência dos clientes. Em complemento, a firma terá que prover financiamento para investir em estoques incrementais. Nessas situações, há trade-offs relevantes a serem considerados entre as variáveis anotadas e, nesse caso, podem surgir conflitos de agência e custos de transações entre os diversos stakeholders do negócio.

Além disso, parte substantiva das pesquisas sobre capital de giro utilizam dados contábeis secundários compostos por diversos indicadores ou variáveis operacionais, econômicas e financeiras, resumidas sob a forma de valores agregados para análise de relações teóricas. Os estudos supõem que essas variáveis não são correlacionadas (García-Teruel \& Martínez-Solano, 2007; Hill, Kelly, \& Highfield, 2010), fato esse que pode dificultar a compreensão do tema. Porém esse pressuposto não tem aderência no mundo real das firmas, e os estudos empíricos a respeito da associação entre as práticas do construto de gestão do capital de giro estão ausentes na literatura contábil-financeira.

Considerando o que foi apresentado, o estudo presente justifica-se tanto pelo fato de suprimir o gap como pela necessidade de compreender o comportamento gerencial dos dirigentes de MPEs no tocante ao controle e ao gerenciamento das práticas de contas do ativo circulante. Outro motivo que contribui com a originalidade deste estudo é a utilização de informações e de percepções obtidas por meio de um levantamento exclusivo de uma amostra de firmas privadas, racionadas de crédito, familiares, com fins lucrativos e com acentuada opacidade informacional em relação às listadas na BM\&FBOVESPA. Em consequência disso, as MPEs são vistas pelo mercado financeiro com de maiores riscos de default, e, assim, sofrem de restrição de acesso ao mercado de crédito, além de operarem em 
uma economia emergente como o Brasil, onde não há, ainda, bancos de dados secundários públicos disponíveis sobre tais firmas.

Como, no Brasil, 99\% das empresas são MPEs, conhecer, estudar e evidenciar a gestão das práticas de capital de giro desses empreendimentos mostra-se como um assunto oportuno e relevante, pois as MPEs respondem pela contratação de parte significativa da mão de obra assalariada no Brasil e, nem sempre, adotam os procedimentos de administração a que, geralmente, as grandes empresas têm acesso.

Nesse contexto, a questão empírica que se busca responder é: como os dirigentes de MPEs percebem a associação entre as práticas de crédito para gerar recebíveis, de caixa e de estoques? Assim, o objetivo deste estudo é analisar o impacto da gestão das práticas de oferta de crédito sobre gestão das práticas de estoques em MPEs.

Este estudo contribui com a literatura para a gestão financeira das MPEs por: (a) identificar quais rotinas de gestão financeira de curto prazo são direcionadores significativos, conforme percepção dos dirigentes de cada construto; (b) mensurar as estimativas dos coeficientes de regressões simultâneas entre direcionadores e variáveis latentes; e (c) estimar os efeitos diretos e indiretos entre oferta de crédito, capital interno e estoques.

\section{Contexto Teórico}

A fundamentação teórica deste estudo leva em consideração as seguintes teorias: (a) a dos custos de transações; (b) a de agência; e (c) a da pecking order.

\section{Custos de transações (CT)}

Coase (1937) partiu da ideia de que a firma pode ser compreendida como um nexo de contratos, e nela existem dois tipos de custos: os de produção, que se realizam no seu interior, e os de transação, com os terceiros. Uma transação ocorre quando uma mercadoria ou serviço é transferido entre interfaces tecnologicamente distintas (Williamson, 1981). Essa teoria fornece o argumento de que as firmas existem porque é mais econômico internalizá-las que recorrer ao mercado livre.

Nesse caso, as organizações criam estruturas hierárquicas e burocráticas custosas para coordenar e controlar tanto as atividades internas como os contratos. Como consequência disso, as rotinas de gestão de estoques são institucionalizadas como mecanismos administrativos para coordenar a eficiência nas transações de compras, enquanto as de análise de crédito e de cobrança se prestam a minimizar os riscos de inadimplência e de créditos incobráveis decorrentes dos investimentos em contratos de vendas a prazo para clientes. As práticas de controle de caixa tornam-se necessárias porque tanto articulam os termos de contratos de clientes-fornecedores-acionistas, como buscam atender o nível de liquidez desejado pelo gestor.

Nessa conjuntura, os CT estão fundamentados: (a) nas suposições comportamentais de racionalidade limitada e de oportunismo dos agentes; e (b) nas dimensões e/ou características das transações: frequência, ativos específicos, incerteza. Na avaliação para concessão de crédito em vendas no crediário, a empresa se depara com muitas incertezas sobre a qualidade de crédito do cliente e, em decorrência disso, incorre em custos de transações para obter informações junto ao SERASA, SPC e outros antes de contratar a operação. Isso ocorre porque há informações ocultas (Akerloff, 1970) dos clientes que são de difícil acesso, tanto, ex-ante como ex-post à venda. Nessa condição, as informações tornam-se assimétricas entre os agentes, e os mecanismos administrativos onerosos para avaliação de risco de crédito e prevenção de perdas como práticas de controle de níveis de inadimplência, de incobráveis, de provisão para devedores duvidosos e outros, são institucionalizados para garantir eficiência plena da firma. 


\section{Teoria de agência}

A literatura econômica e a financeira atual têm a contribuição teórica de vários autores, que argumentaram que a separação da função de administrar da função de controlar necessitava de uma estrutura de governança corporativa (Berle \& Means, 1932), em razão dos potenciais conflitos de interesses advindos do relacionamento do principal-agente (Ross, 1973), cujo ônus foi cunhado como custos de agência em razão da assimetria de informações entre agentes (Jensen \& Meckling, 1976). Esses custos surgem em virtude do alinhamento incompleto de interesses entre as partes de um contrato. Consequentemente, para estes serem acompanhados, há a necessidade de informações, as quais são essenciais para controlar o desempenho de curto prazo e as consequências das ações dos agentes no longo prazo.

No contexto das firmas privadas e não listadas em Bolsas, e em especial nas MPEs, o foco das relações de agência deixa de ser entre administrador-acionista e passa a envolver outras personagens, como, por exemplo, clientes que contratam crédito nas compras a prazo, fornecedores que ofertam crédito comercial para a venda de mercadorias a prazo e instituições financeiras que podem suprir as necessidades de capital de giro das firmas, concedendo crédito na carteira de desconto de recebíveis e/ou em operações de empréstimos de curto prazo. Como decorrência de informações assimétricas, os problemas de agência surgem em duas categorias: seleção adversa e risco moral. A seleção adversa ocorre ex-ante enquanto o risco moral envolve ex-post à contratação, como, por exemplo, o cliente atrasar ou não honrar o pagamento de parcelas do crediário. O enfrentamento desses eventos impõe ao principal um ônus para monitorar os agentes.

Para minimizar os conflitos de interesses, são instituídos processos de monitoramento e de controle das ações dos gerentes. Esses mecanismos de monitoramento podem ser tanto internos como externos. Exemplos são os que as firmas empregam no processo de análise e concessão de crédito a clientes, e de cobrança. Para isso, há a necessidade de informações sobre os clientes, as quais são difíceis e custosas, que, no caso, implicam custos para serem obtidas. Nesse processo de relacionamento, há custos de agência tanto para os agentes como para o principal (Jensen \& Meckling, 1976).

Nesse contexto, a adoção de práticas de controle de gestão de caixa, como as de orçamento de caixa, dos prazos médios de pagamento e de recebimento e de identificação de linhas bancárias de empréstimos para capital de giro são relevantes para orientar as decisões de compras de mercadorias nas MPEs. A retenção de caixa gerado internamente nas MPEs pode servir de funding para a compra de estoques adicionais e/ou investimento em outros ativos.

\section{Teoria da pecking order (TPO)}

A TPO (Myers, 1984) parte da premissa de que há conflitos de interesses potenciais na repartição de riqueza entre acionistas antigos e novos, caso a empresa emita novas ações para financiar investimentos subótimos, estabelecendo, assim, um problema de agência entre proprietários e investidores. Esse fato ocorre em razão da existência de assimetria de informações sobre novos projetos e iniciativas de negócios e, nessas condições, os investidores exigem retornos maiores, o que implica subavaliar as ações da firma. Como consequência dessa possibilidade, os acionistas atuais resistem em aprovar novas emissões do capital patrimonial.

Nesse contexto, a TPO propõe que os gestores das firmas deveriam ordenar as fontes de recursos de capital de forma hierárquica e assimétrica, e estabelecer preferências nas suas decisões de estrutura de capital, priorizando as fontes internas (caixa gerado pelas operações); em seguida, as externas de maior facilidade e menor custo (emissão de títulos de dívidas de crédito bancário e/ou comercial), e, por último, as externas de maior dificuldade e maior custo (emissão de novas ações). Nessas circunstâncias, essas firmas sofrem restrição de acesso ao crédito bancário, em razão dos severos problemas de assimetrias informacionais existentes, o que gera barreira de crescimento. Assim, o caixa incremental gerado internamente pelas vendas decorrentes do aumento de oferta de crédito, o crédito comercial e, 
eventualmente, o bancário, são fatores relevantes a serem considerados pelos gestores nas decisões sobre estoques, quando a firma se encontra contingenciada financeiramente.

\section{Modelo Teórico e Proposições}

A Figura 1, a seguir, ilustra o modelo teórico deste estudo. A descrição das variáveis indicadoras reflexivas dos construtos constam na Tabela 1, da próxima seção.

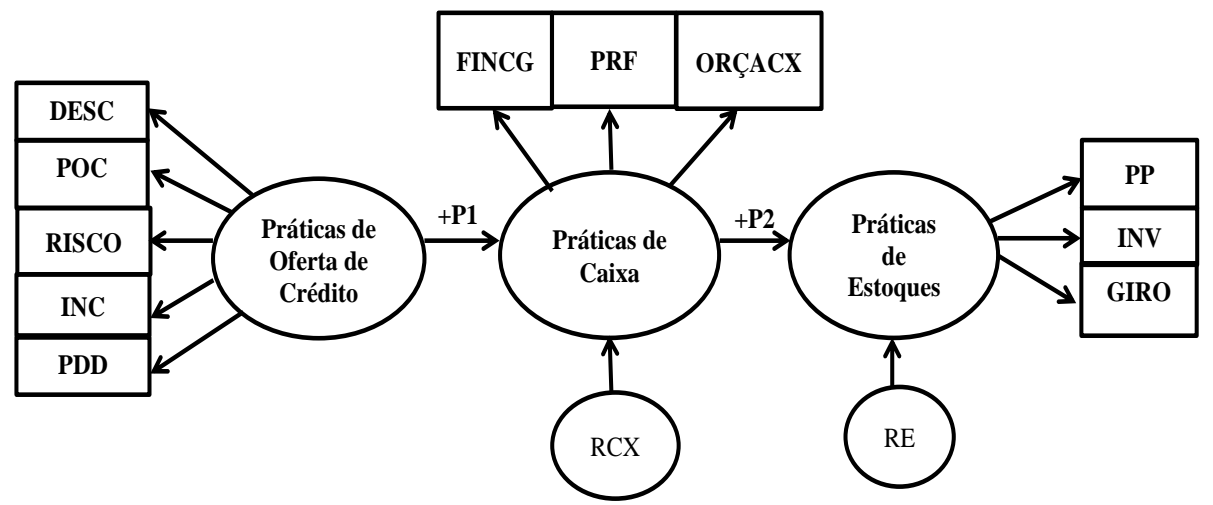

Figura 1. Modelo Teórico de Proposições de Associações

As variáveis latentes Gestão de caixa e de Estoques são variáveis endógenas no modelo de regressão estrutural. RCX e RE são os distúrbios de causas omitidas nas variáveis endógenas. Fonte: Elaborada pelo autor.

A gestão das práticas de estoques são influenciadas tanto pela disponibilidade de recursos financeiros como pelo nível de receitas planejado. $\mathrm{O}$ aumento das vendas requer que a firma faça investimentos marginais em estoques para atender à demanda prevista. No entanto, essa decisão tem revelado resultados contraditórios. Kieschnick, Laplante e Moussawi (2012) mostram que o dólar incremental investido em crédito para os clientes tem um efeito muito maior na riqueza do acionista que o dólar incremental investido em estoques. Isso sugere que a política de crédito (comercial ou ao consumidor) da empresa é uma parte muito importante da gestão de capital de giro.

A decisão de ampliar o volume de crédito objetiva o aumento de vendas, e é um incentivo que a firma oferece aos clientes para adquirir os produtos desejados. A venda a prazo muda o perfil de liquidez, pois a empresa permuta o estoque em títulos recebíveis de curto prazo. Contudo, essa transação de investimento é onerosa e de risco para a empresa, pois há a necessidade de informações para a análise prévia de qualidade de crédito do comprador.

Nessas situações, as firmas se defrontam tanto com o problema de seleção adversa dos clientes como com o de risco moral pela falta de pagamento, o que pode afetar a liquidez do negócio. Paul e Boden (2011) atribuem os atrasos às práticas pobres de gestão financeira das empresas. Conforme recomenda a literatura de finanças corporativas de curto prazo, as firmas podem mitigar esses riscos estabelecendo políticas microprudenciais de crédito, ao implantar um conjunto coerente de práticas de gestão de crédito e de cobrança. Assim, é comum as firmas institucionalizarem as melhores práticas de gestão de acordo com as orientações de associações patronais do setor de atuação econômica.

Conforme recomendam Weston e Brigham (2000), uma política de crédito deve incluir as seguintes variáveis: (a) padrões de crédito, isto é, o risco máximo aceitável na conta clientes, para estimar as perdas com recebimentos incobráveis. A literatura de crédito mostra que há uma correlação significativa e positiva entre os custos de agência e de transações e a qualidade do crédito. Nesse sentido, o trade-off entre custos de investimento e lucros, ambos marginais, deve ser analisado, visto que grandes volumes de capital aplicado em recebíveis de baixa qualidade de crédito pode resultar em maiores custos de capital para a firma. Os riscos de crédito devem incluir 5 fatores (5C's), são eles: caráter, capacidade, 
capital, colateral e condições (a avaliação desses fatores implica custos de transações para a firma); (b) o período de crédito, que é o prazo de duração do contrato para pagamento da dívida. O perfil da conta clientes possibilita calcular o prazo médio de recebimento (pmr) da carteira de recebíveis. A ampliação dos prazos de pagamentos estimula vendas, mas também há um custo adicional de capital investido em recebíveis (Weston \& Brigham, 2000); (c) o desconto, que serve como um incentivo para o cliente antecipar o pagamento da dívida. Quanto maior for este incentivo, menor a probabilidade de atrasos, de perdas com os incobráveis e do pmr. O impacto desses eventos contribui positivamente para a firma obter volumes de caixa interno maiores; (d) a política de cobrança para casos de atrasos de pagamentos e de default dos contratos. É útil advertir que existem fortes interações entre as variáveis enunciadas, e esse aspecto pode dificultar o entendimento das implicações de mudanças das práticas sobre o desempenho nas MPEs.

O motivo para adoção dessas rotinas nas firmas objetiva assegurar que o total de capital investido na conta clientes (títulos recebíveis) se transforme, integralmente, em caixa. Assim, é de se esperar que, quanto mais frequente e coordenada for a gestão das práticas de análise e de concessão de crédito, melhor será a gestão das práticas de caixa das firmas. Assim, com base nesses argumentos, formula-se a primeira proposição:

$\mathbf{P}_{1}$ : A gestão das práticas de oferta de créditos está associada positivamente à gestão de práticas de caixa nas MPEs.

O controle dessas práticas deve ser eficiente, porque, em firmas financeiramente restritas, o caixa gerado internamente pode ser usado para formar um colchão de liquidez para eventuais amenizar os eventuais choques de demanda e de crédito. Isso é relevante porque os créditos comerciais, por si só, são insuficientes para financiar os estoques das firmas (S. A. Yang \& Birge, 2013). O estudo de Carvalho e Schiozer (2012) em MPEs aponta que, em média, 67\% das compras são feitas por meio de crédito comercial, o que corrobora os de S. A. Yang e Birge (2013). Nessa situação, os dirigentes necessitam buscar outras formas de financiamento para complementar aqueles obtidos junto aos fornecedores.

Contudo, a teoria da agência prevê os conflitos de agência entre devedor - credor, porque, nas MPEs, existem acentuadas assimetrias de informações. Assim, elas são consideradas de alto risco de inadimplência e de default pelo mercado financeiro e, nessas circunstâncias, sofrem de restrição de acesso pleno ao crédito bancário. Além desses aspectos os custos de transação e de agência das instituições financeiras, e as MPEs são superiores às das firmas de maiores porte. Isso faz com que o custo financeiro dos empréstimos para as MPEs seja também elevado.

Nesse ambiente contingencial de mercado, as firmas necessitam formar uma reserva de caixa para garantir liquidez das operações e obter flexibilidade nas decisões. As firmas têm três motivos (Opler, Pinkowitz, Stulz, \& Williamson, 1999) para manterem saldos de caixa: (a) o de transações - para atender as atividades de comprar e vender. Nesse caso, os prazos médios, de recebimento e de pagamentos, são determinantes do orçamento de caixa da firma; (b) o de precaução - para suprir eventuais falhas de previsão de entradas e saídas de caixa (orçamento de caixa); e (c) especulação - para aproveitar oportunidades de lucros esporádicos.

Entretanto, a teoria de agência entende que dispor de maiores volumes de saldo de caixa em firmas com gestão profissional pode implicar custos de monitoramento do agente pelo principal em razão de conflitos de interesse decorrente da possibilidade do gestor vir a investir em projetos com VPL negativos. Em adição, Faulkender e Wang (2006) mostram evidências de que o investimento incremental de cada US $\$ 1,00$ em caixa, em firmas norte-americanas, destrói a riqueza dos acionistas. Porém o impacto dessa decisão em MPEs que operam em economias emergentes pode se dar em direção oposta à encontrada pelos citados autores.

S. A. Yang e Birge (2013) informam que, mesmo as firmas varejistas norte-americanas, as quais operam em uma economia desenvolvida, não usam, exclusivamente, créditos institucionais, mas um portfólio de fontes - caixa interno, créditos comerciais e dívidas de curto prazo, para financiar o investimento em estoques. Destas, o capital interno emerge como a fonte de fundos preferencial dos 
gestores na aquisição de estoques (S. A. Yang \& Birge, 2013), conforme o previsto na TPO (Myers \& Majluf, 1984), pois é menos custoso e, portanto, mais atrativa que as fontes de financiamentos externas.

Com base nessas evidências, depreende-se que o capital interno é a principal fonte de fundos para financiar investimentos corporativos (Islam \& Mozundar, 2007; Lamont, 1997). Isso mostra a confiança dos dirigentes na geração de caixa próprio. Em especial, nas firmas que são restritas financeiramente pelo mercado de crédito. Baum, Schafer e Talavera (2011) encontraram resultados em linha com a POT de Myers e Majluf (1984), a qual sugere que firmas preferem fundos internos a externos. Se seu fluxo de caixa gerado é maior que o dispêndio de capital, a firma pode investir em ativos líquidos e vice versa. Um desses ativos podem ser os estoques.

Do ponto de vista econômico, os principais determinantes do investimento em estoques são: (a) o nível de vendas; (b) a duração e a natureza do processo de produção ou de logística; e (c) a durabilidade do produto final. A partir desses aspectos, a gestão de estoque requer a adoção de práticas de controle como, por exemplo, o valor do investimento, o giro do estoque, o ponto de pedido de cada item e, em alguns casos, o cálculo de lotes econômicos de compras.

Essas práticas são relevantes porque os estoques podem ser a principal fonte de geração de valor nas MPEs. Assim, os gestores precisam destinar esforços nessa área, pois há CT's que podem impactar o resultado do negócio. Então, formula-se a proposição 2.

$\mathbf{P}_{2}$ : A gestão das práticas de caixa está associada positivamente à gestão das práticas de estoques nas MPEs.

\section{Métodos e Procedimentos}

A Tabela 1, a seguir, elenca as rotinas de gestão de capital de giro, mostradas na Figura 1 da seção anterior, que fizeram parte de questionário desenvolvido por Howorth e Westhead (2003). A escala de frequência de 5 pontos - variando de $1=$ nunca até $5=$ muito frequentemente - foi traduzida de forma reversa, para assegurar o sentido universal dos conceitos contidos nos quesitos pesquisados. Desse modo, o presente estudo utilizou a metodologia recomendada por Balbinotti, Benetti e Terra (2006) para realizar a tradução do instrumento de coleta de dados, quando são replicados em culturas diferentes.

Tabela 1

\section{Rotinas de Gestão de Capital de Giro e Literatura de Apoio}

\begin{tabular}{|c|c|c|c|}
\hline Rotinas & Código & Interpretação & Literatura de apoio \\
\hline 1) Giro de Estoques & GIRO & $\begin{array}{l}\text { Número de vezes em que o } \\
\text { estoque médio é vendido em } \\
\text { um período. }\end{array}$ & $\begin{array}{l}\text { Brigham e Ehrhardt (2007); Preve e } \\
\text { Sarria-Allende (2010); Gitman (2010) }\end{array}$ \\
\hline $\begin{array}{l}\text { 2) Nível Investimento em } \\
\text { Estoques }\end{array}$ & INV & $\begin{array}{l}\text { Valor monetário alocado em } \\
\text { compras de matérias-primas } \\
\text { e/ou de produtos acabados }\end{array}$ & $\begin{array}{l}\text { Brigham e Ehrhardt (2007); Preve e } \\
\text { Sarria-Allende (2010); Gitman (2010) }\end{array}$ \\
\hline 3) Ponto de Pedido & $\mathrm{PP}$ & $\begin{array}{l}\text { Quantidade física do item para } \\
\text { ordem de compra }\end{array}$ & $\begin{array}{l}\text { Ross, Westerfield e Jordan (2000); } \\
\text { Gitman (2010) }\end{array}$ \\
\hline $\begin{array}{l}\text { 4) Prazos de Crédito } \\
\text { Ofertados a Clientes }\end{array}$ & POC & $\begin{array}{l}\text { Condições e duração do valor } \\
\text { financiado }\end{array}$ & $\begin{array}{l}\text { Brigham e Ehrhardt (2007); Gitman } \\
\text { (2010); Preve e Sarria-Allende (2010) }\end{array}$ \\
\hline
\end{tabular}


Tabela 1 (continuação)

\begin{tabular}{|c|c|c|c|}
\hline Rotinas & Código & Interpretação & Literatura de apoio \\
\hline $\begin{array}{l}\text { 5) Política de Desconto a } \\
\text { Clientes por pagamentos à } \\
\text { vista ou antecipados }\end{array}$ & DESC & $\begin{array}{l}\text { Taxa porcentual ofertada para o } \\
\text { cliente antecipar valores a } \\
\text { pagar. }\end{array}$ & $\begin{array}{l}\text { Brigham e Ehrhardt (2007); Preve e } \\
\text { Sarria-Allende (2010) }\end{array}$ \\
\hline $\begin{array}{l}\text { 6) Créditos Incobráveis de } \\
\text { Clientes }\end{array}$ & INC & $\begin{array}{l}\text { Valor financeiro com perdas } \\
\text { realizadas }\end{array}$ & $\begin{array}{l}\text { Caouette, Altmann e Narayanan } \\
\text { (2009); Sicsú (2010) }\end{array}$ \\
\hline $\begin{array}{l}\text { 7) Créditos Duvidosos da } \\
\text { Carteira de recebíveis }\end{array}$ & PDD & $\begin{array}{l}\text { Valor estimado de perdas nas } \\
\text { vendas a prazo }\end{array}$ & Caouette et al. (2009); Sicsú (2010) \\
\hline $\begin{array}{l}\text { 8) Risco de Crédito de } \\
\text { Clientes }\end{array}$ & RISCO & $\begin{array}{l}\text { Critério interno para medir o } \\
\text { risco da concessão do crédito. }\end{array}$ & $\begin{array}{l}\text { Brigham e Ehrhardt (2007); Caouette } \\
\text { et al. (2009) }\end{array}$ \\
\hline $\begin{array}{l}\text { 9) Prazo de Pagamento } \\
\text { recebidos de Fornecedores }\end{array}$ & PRF & $\begin{array}{l}\text { Condições para amortizar o } \\
\text { financiamento por meio do } \\
\text { crédito comercial negociado. }\end{array}$ & $\begin{array}{l}\text { Ross et al. (2000); Brigham e Ehrhardt } \\
\text { (2007); Gitman (2010) }\end{array}$ \\
\hline $\begin{array}{l}\text { 10) Fontes de } \\
\text { Financiamento }\end{array}$ & FINCG & $\begin{array}{ll}\text { Identificação e análise } & \text { de } \\
\text { alternativas de captação } & \text { de } \\
\text { recursos externos } & \end{array}$ & $\begin{array}{l}\text { Ross et al. (2000); Brigham e Ehrhardt } \\
\text { (2007); Preve e Sarria-Allende (2010); } \\
\text { Gitman (2010) }\end{array}$ \\
\hline $\begin{array}{l}\text { 11) Uso de Orçamento de } \\
\text { Caixa }\end{array}$ & ORÇACX & $\begin{array}{l}\text { Instrumento gerencial que } \\
\text { aponta o comportamento } \\
\text { provável de entradas e saídas } \\
\text { de dinheiro. }\end{array}$ & $\begin{array}{l}\text { Weston e Brigham (2000); Ross } \text { et al. } \\
\text { (2000); Brigham e Ehrhardt (2007); } \\
\text { Gitman (2010) }\end{array}$ \\
\hline
\end{tabular}

Nota. Esta Tabela exibe as 11 rotinas utilizadas na gestão de capital de giro das empresas. Fonte: Elaborada pelo autor.

A primeira coleta de dados, com 198 observações, e a segunda, com 183, foram obtidas por conveniência e aconteceram em cada semestre de 2008 (pré-crise), enquanto a terceira, com 175, de natureza aleatória, foi efetuada no segundo semestre de 2010. Os dados da última coleta serviram de referência para validar a escala de mensuração aplicada ao modelo final. Os resultados foram não significativos (p-valor $<1 \%$ ), indicando que a escala de mensuração se comporta de maneira semelhante à da primeira e à da segunda coleta.

O teste $\mathrm{t}$ de Student foi aplicado nas três amostras (p-valor $<1 \%$ ), sob o qual não foram identificadas diferenças amostrais significantes entre as médias de cada rotina de administração de capital de giro. Esse procedimento visou mitigar a possível existência de vieses entre as amostras. Assim, para executar a metodologia da pesquisa proposta e realizar o tratamento estatístico, juntaram-se os dados das três amostras.

A estratégia de obtenção de dados utilizada nesse survey foi por coleta transversal, por meio de questionário estruturado, com apoio de entrevistadores e via correio postal, ou pela web, com data limite para retorno. As firmas que receberam o questionário foram selecionadas, aleatoriamente, a partir de base de dados de duas associações patronais. Não houve esforço para a recuperação de não respondentes. A taxa de respostas válidas foi de $18 \%$.

O amplo uso e a aceitação de surveys em estudos estrangeiros, sobre finanças, foram sistematizados por três editores de periódicos internacionais e podem ser vistos em Baker, Singleton e Veit (2011). De acordo com Taylor-Powell e Hermann (2000), o uso do método survey é mais bem recomendado quando alguns aspectos não podem ser observados diretamente ou porque seria impossível ou impraticável para o pesquisador observar diretamente o objeto de pesquisa. Quando o objeto de pesquisa são pequenas e médias empresas, as informações financeiras e gerenciais não são publicamente disponíveis, e o método de survey tem o papel de suprimir essa lacuna, para gerar novos conhecimentos empíricos em Finanças.

As coletas foram realizadas em 32 cidades dos Estados de Minas Gerais e de São Paulo. Esses estados são representativos na economia, visto responderem, em conjunto, por, aproximadamente, 43,0 
$\%$ do PIB do Brasil. O questionário foi respondido por dirigentes de 556 empresas, gerando o perfil, por porte e ilustrado na Figura 2, a seguir. Como se pode observar, a participação das MPEs nessa amostra é de, aproximadamente, $80 \%$. O critério escolhido para categorizar as empresas segue o modelo do Serviço Brasileiro de Apoio às Micro e Pequenas Empresas (Sebrae), que baseia no número de funcionários, sendo microempresa aquela com até nove funcionários, se empresa comercial, e até 19 funcionários, se industrial, e como pequena empresa aquela com dez a 19, se comercial, e de 20 a 49, se industrial. Neste estudo, foram incluídas as empresas não financeiras e as privadas com até 49 funcionários, num total de 432, independentemente do setor econômico. A amostra conta com uma diversidade de empresas em atividade e pertencentes ao mais amplo espectro de setores da economia, o que torna importante a sua representatividade

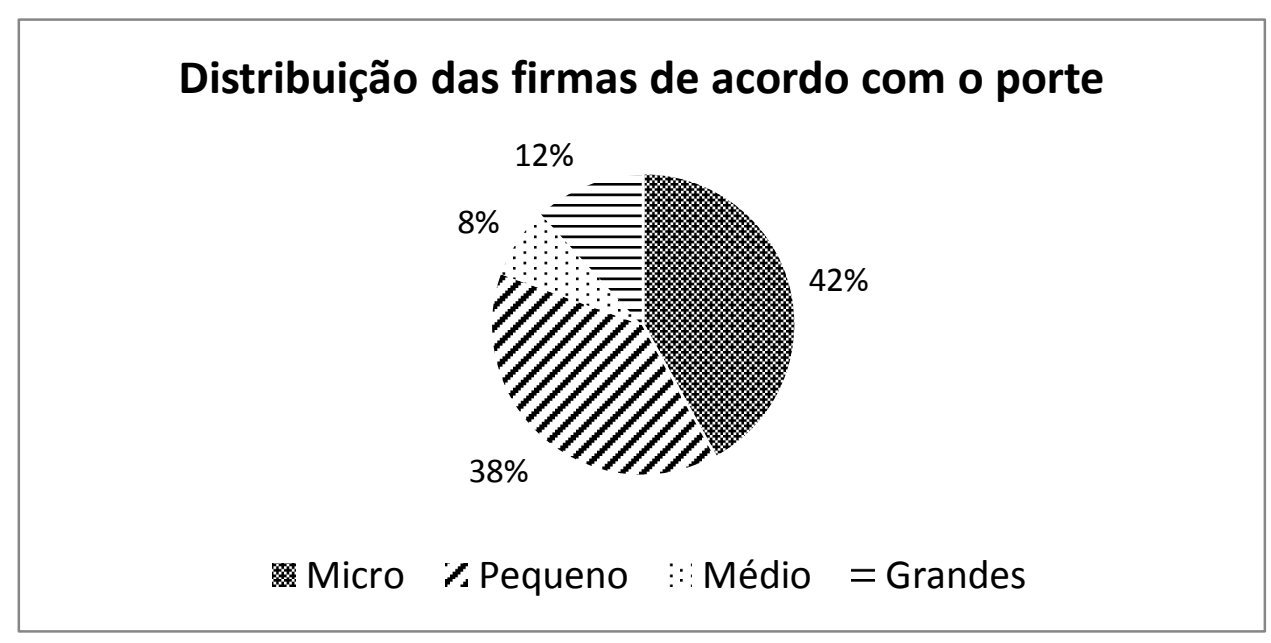

Figura 2. Distribuição das Firmas de Acordo com o Porte

O respondente foi o dirigente principal e/ou fundador da firma. As observações de empresas de seguros, factoring e de consórcios, bem como das empresas públicas e ONGs, e itens do questionário com missing values, foram excluídas do banco de dados.

\section{Limitações do estudo}

A análise e a interpretação de resultados por surveys exigem cautela em razão dos potenciais vieses que podem surgir por parte: (a) dos respondentes pelas não respostas, por respostas não verdadeiras e/ou respondidas conforme o pesquisador gostaria de receber; e (b) do entrevistador por conduzir de modo inadequado a entrevista. Na análise desse tipo de estudo, há que se considerar ainda os potenciais erros nas variáveis de especificação do modelo, erros de mensuração e erros estatísticos

Nesse caso, o presente estudo tem várias limitações. Primeira, as observações repercutem tão somente a percepção dos gestores da amostra pesquisada em MPEs mineiras e paulistas e não devem ser generalizáveis. As respostas são subjetivas e representam a opinião/visão do proprietário do negócio, e pode ser que não ocorra isomorfismo entre os demais dirigentes (Baker, Singleton, \& Veit, 2011). Segunda, o estudo pressupõe que as práticas empregadas representam exatamente tudo o que se precisa sobre a percepção das dimensões latentes da gestão do capital de giro. Terceira, em razão de restrições orçamentárias deste projeto e dos tipos de firmas objeto do presente estudo (privadas e não listadas na BM\&FBOVESPA), na composição da amostra não se buscou qualquer consistência em termos de distribuição geográfica, por tamanho ou por setor de atuação. Ou seja, esse levantamento gerou ampla heterogeneidade de dados para análise e melhor entendimento do tema. Quarta, não se coletaram dados contábeis ou financeiros das firmas. Quinta, o uso da escala ordinal em modelos estruturais pode distorcer os resultados pois viola um dos pressupostos da SEM que orienta medir os dados em escala métrica intervalar ou de razão, ou seja, mensurar variáveis com o mais alto nível de precisão (Hair, Anderson, Tatham, \& Black, 2005). 


\section{Tratamento dos dados}

Na primeira etapa, foram calculadas as frequências das respostas da amostra para contrastá-la com as dos dirigentes do Reino Unido. Em seguida, foram feitas a análise fatorial exploratória (AFE) e a análise fatorial confirmatória (AFC), a validação do construto e da escala de medida. Por último, procedeu-se à estimação dos coeficientes das regressões entre variáveis latentes, dos erros e dos resíduos, por meio da regressão estrutural (RE). Utilizaram-se os softwares SPSS e AMOS v18, para tratamento estatístico dos dados.

Para alcançar o objetivo proposto e tendo em mente as relações interdependentes entre indicadores da gestão de capital de giro e a simultaneidade de decisões de compra, venda e produção, recorreu-se às técnicas de modelagem com equações estruturais (SEM), que possibilitaram tanto estimar os coeficientes como tratar, concomitantemente, os erros de mensuração.

A decisão dessa escolha metodológica deve-se ao fato de também existirem relações de dependência (ou de mediação) entre duas variáveis independentes que afetam a(s) variável(is) dependente(s), situação na qual podem ocorrer problemas de multicolinearidade e de efeitos indiretos na variável prevista.

A preocupação da SEM é com a ordem das variáveis (Klem, 1995). Por exemplo, na regressão, a variável X influencia a Y; na SEM, "a variável dependente em uma equação pode ser a independente em outra(s)" (Hair et al., 2005, p. 471). Nessas situações, conforme os citados autores, os pressupostos da técnica de regressão linear múltipla limitam o seu uso para estimar os coeficientes.

Além disso, C. Chang, Lee e Lee (2009) apontam que a análise de regressão linear (a) não controla os erros de mensuração da escala; e (b) lida com uma variável dependente por vez. Em contraste, a SEM não só permite ao pesquisador controlar os erros de medida das variáveis observadas, mas também se presta ao manuseio de mais de uma variável dependente (construto de gestão de práticas de caixa e de estoques), como é o caso do modelo idealizado nesta análise. A referida técnica é especialmente útil para explorar modelos hipotéticos formados por inter-relacionamentos complexos entre variáveis indicadoras e construtos teóricos.

Do ponto de vista empírico, Titman e Wessels (1988) escolheram empregar a SEM como estratégia para superar alguns problemas da análise de regressão múltipla associados com a estimação de parâmetros, quando se usam no estudo proxies para atributos teóricos não observáveis. Posteriormente, outros estudos em finanças (C.-C. Yang, Lee, Gu, \& Lee, 2010; C. Chang, Lee, \& Lee, 2009; Ling, Naranjo, \& Nimalendran, 2000; Maddala \& Nimalendran, 1995; Örtqvist, Rahman, \& Selvarajah, 2006) também adotaram essa técnica estatística para estimar as especificações dos modelos teóricos.

Inicialmente, empregou-se a análise fatorial exploratória (AFE) aos dados, para ter-se uma noção dos possíveis componentes principais e validar a escala para a amostra. Com base nesses resultados, realizou-se a análise fatorial confirmatória (AFC) de primeira ordem, para testar se, efetivamente, os indicadores da escala mediram uma dimensão latente particular. De acordo com Ling, Naranjo e Nimalendran (2000), a AFC fornece uma estrutura analítica mais robusta que os métodos estatísticos tradicionais, que não levam em conta os erros de mensuração nas proxies empregadas (por exemplo, a abordagem dos mínimos quadrados ordinários supõe que as variáveis são isentas de erros de medida).

As vantagens de estimativas de efeitos com abordagens confirmatórias incluem a habilidade em: (a) especificar modelos de mensuração distinto que são conceitualmente críveis; (b) determinar a variância do método em cada indicador; e (c) obter melhores estimativas dos relacionamentos dos indicadores nos fatores e entre os construtos. Outra dimensão que reforça o uso da CFA neste estudo é a habilidade da técnica em determinar quão bem o modelo de mensuração é equivalente entre grupos de firmas ou desses ao longo do tempo. Esse aspecto é especialmente importante para eliminar possíveis vieses de medida das variáveis indicadoras. Além disso, as variáveis previsoras das práticas financeiras deste estudo foram observadas em escala intervalar, o que é consistente com as suposições da AFC. Para 
a avaliação do modelo, foram utilizadas as estatísticas de bondade de qualidade de ajustes mais comumente empregadas na avaliação de modelos estruturais (Byrne, 2001) - CMIN $\left(\chi^{2}\right)$; NFI; CFI e RMSEA - e os Modification Indexes (MI) para se realizarem as reespecificações dos modelos e as reestimações dos coeficientes de regressão e de erros de mensuração dos dados.

\section{Análise de Dados e Resultados}

A distribuição de frequência de revisão de cada prática entre dirigentes de MPEs britânicas e brasileiras é exibida na Tabela 3, a seguir.

Os resultados sugerem, com base na percepção dos dirigentes brasileiros, que a disposição a controlar destes é diferente (p-valor $<10 \%$ ) da dos britânicos, e que aqueles apresentam uma frequência de gestão de capital de giro maior, exceto quanto às rotinas de prazo médio de recebimento e de orçamento de caixa, cujo comportamento é estatisticamente igual. Essas diferenças podem ser explicadas sobre a existência de uma maior necessidade de revisar as políticas de capital de giro no Brasil em comparação ao Reino Unido, devido ao menor desenvolvimento do sistema financeiro e aos diferentes estágios de desenvolvimento das economias.

Tais aspectos dificultam o acesso das MPEs brasileiras ao sistema bancário, e isso faz com que a otimização no uso dos recursos de curto prazo implique retorno marginal maior no Brasil do que no Reino Unido em razão dos custos de transações e de agência entre dirigentes e credores aqui serem superiores aos de lá. Ou seja, os resultados sugerem que o comportamento dos dirigentes mineiros e paulistas quanto à disposição em controlar as rotinas financeiras estão mais alinhados às orientações teóricas dos custos de transações, de agência e da pecking order do que o dos britânicos. 
Tabela 3

Frequência de Revisão de Práticas de Gestão

\begin{tabular}{|c|c|c|c|c|c|c|c|c|c|c|c|c|c|c|c|c|c|}
\hline \multirow[t]{2}{*}{ Práticas de gestão } & \multicolumn{2}{|c|}{ Nunca } & \multicolumn{2}{|c|}{$\begin{array}{l}\text { Algumas } \\
\text { vezes }\end{array}$} & \multicolumn{2}{|c|}{ Às vezes } & \multicolumn{2}{|c|}{ Frequentemente } & \multicolumn{2}{|c|}{$\begin{array}{c}\text { Muito } \\
\text { Frequentemente }\end{array}$} & \multicolumn{2}{|c|}{ Média } & \multicolumn{2}{|c|}{$n$} & \multicolumn{2}{|c|}{ Desvio padrão } & \\
\hline & UK & $\mathrm{Br}$ & UK & $\mathrm{Br}$ & UK & $\mathrm{Br}$ & UK & $\mathrm{Br}$ & UK & $\mathrm{Br}$ & UK & $\mathrm{Br}$ & UK & $\mathrm{Br}$ & UK & $\mathrm{Br}$ & \\
\hline Giro de estoque & 40,8 & 12,4 & 27,5 & 14,2 & 17,0 & 14,2 & 11,1 & 38,8 & 3,6 & 20,4 & 2,09 & 3,41 & 306 & 451 & 1,88 & 1,30 & $6,86^{* * * *}$ \\
\hline Investimentos em estoques & 36,0 & 17,7 & 18,5 & 18,1 & 25,3 & 16,6 & 13,6 & 37,7 & 6,5 & 9,9 & 2,36 & 3,04 & 308 & 453 & 1,74 & 1,29 & $3,80^{* *}$ \\
\hline Ponto de pedido de estoques & 40,3 & 20,4 & 19,0 & 15,0 & 20,3 & 17,3 & 13,4 & 36,1 & 6,9 & 11,2 & 2,28 & 3,03 & 305 & 446 & 1,78 & 1,33 & $4,07 * *$ \\
\hline Prazos ofertados aos clientes & 30,2 & 19,7 & 28,6 & 26,1 & 20,8 & 21,3 & 13,0 & 27,9 & 7,5 & 5,0 & 2,39 & 2,72 & 308 & 456 & 1,72 & 1,21 & 1,88 \\
\hline Política de desconto a clientes & 70,1 & 20,7 & 15,8 & 29,5 & 7,2 & 25,1 & 4,6 & 21,2 & 2,3 & 3,5 & 1,53 & 2,57 & 304 & 458 & 2,28 & 1,14 & $4,67 * * *$ \\
\hline Créditos incobráveis de clientes & 38,8 & 24,6 & 25,0 & 28,3 & 17,8 & 12,9 & 10,9 & 29,2 & 7,6 & 5,0 & 2,23 & 2,62 & 304 & 459 & 1,80 & 1,27 & $2,07 *$ \\
\hline Créditos duvidosos & 31,5 & 24,7 & 30,2 & 25,1 & 20,7 & 15,7 & 12,1 & 26,6 & 5,6 & 7,9 & 2,30 & 2,68 & 305 & 458 & 1,76 & 1,31 & $2,07^{*}$ \\
\hline Risco de crédito de clientes & 28,9 & 18,1 & 32,5 & 24,8 & 22,7 & 14,7 & 11,7 & 33,3 & 4,2 & 9,1 & 2,30 & 2,90 & 308 & 463 & 1,76 & 1,29 & $3,37 * *$ \\
\hline Prazos recebido de fornecedores & 25,5 & 12,8 & 31,9 & 27,3 & 27,4 & 17,4 & 10,0 & 33,4 & 5,2 & 9,1 & 2,37 & 2,99 & 310 & 461 & 1,73 & 1,22 & $3,49 * *$ \\
\hline Financiamento do capital de giro & 32,5 & 20,4 & 31,5 & 18,9 & 19,6 & 14,1 & 9,6 & 37,3 & 6,8 & 9,3 & 2,27 & 2,96 & 311 & 461 & 1,78 & 1,32 & $3,82 * *$ \\
\hline Uso do orçamento de caixa & 29,7 & 38,0 & 21,9 & 19,4 & 22,6 & 11,9 & 12,3 & 26,1 & 13,5 & 4,5 & 2,58 & 2,40 & 310 & 463 & 1,65 & 1,34 & $-1,09$ \\
\hline
\end{tabular}

Nota. A Tabela exibe as frequências de revisão das práticas britânicas e brasileiras. Fonte para resultados britânicos: Howorth, C., \& Westhead, P. (2003). The focus of working capital management in UK small firms. Management Accounting Research, 14(2), 94-111. doi: 10.1016/S1044- 5005(03)00022-2. Fonte dos resultados brasileiros: elaborado pelo autor.

$* * *$ valores significativos $\mathrm{p}<0,01$. ** valores significativos $\mathrm{p}<0,05 . *$ valores significativos $\mathrm{p}<0,1$ 
Por exemplo, nas empresas da amostra, $80 \%$ dos executivos afirmam que revisam, com alguma frequência, as práticas de política de descontos a clientes, para incentivar a antecipação de pagamentos parcelados ou à vista. Ou seja, as empresas com pouco acesso ao mercado de crédito tradicional controlam, com alguma frequência, essa prática como meio de fazer caixa e acelerar o giro do estoque. Consequentemente, as questões inerentes à gestão de estoques também passam a receber mais atenção de controle dos gestores. O nível investimento em estoque esteve sob controle com alguma frequência, por $82 \%$ dos dirigentes nacionais. $\mathrm{O}$ prazo de pagamento a fornecedores e o giro de estoques são as rotinas com maior enfoque de controle dos dirigentes.

Em seguida, as MPEs da amostra foram analisadas usando as técnicas de modelagem de equações estruturais (SEM). Os modelos de mensuração e de regressão estrutural foram utilizados para identificar a validade da escala aplicada e do construto teórico de gestão de capital de giro, para testar as proposições formuladas, respectivamente. O objetivo da SEM é testar quão bem o modelo hipotetizado se ajusta adequadamente aos dados da amostra, usando a matriz de covariâncias. Para isso, é preciso verificar se o modelo proposto é multidimensional e plausível, ou não. A relação crítica de 10:1 entre respondentes/quantidade de itens da escala recomendada na literatura de modelagem de equações estruturais foi alcançada. Neste estudo, a relação foi de 39:1.

\section{Análise fatorial confirmatória}

Os resultados mostraram-se significativos para representar o construto de gestão de capital de giro em três dimensões latentes, assim nomeadas e simbolizadas - gestão de oferta de crédito a clientes (oferta de crédito); gestão de caixa (fluxo de caixa); e gestão de estoques (estoques) - com um mínimo de dois indicadores por componente principal. O método de estimação usado foi o da máxima verossimilhança.

Os itens da escala - giro de estoques, financiamento externo e orçamento de caixa - foram excluídos do modelo inicial por apresentarem valores de comunalidades inferiores a 0,30 , altos valores de resíduos, e de variâncias explicadas inferiores a 0,20. Essas exclusões têm suporte teórico substantivo, pois a gestão da rotina ponto de pedido repercute o conhecimento do giro do estoque na decisão de compra de estoques. Para os dirigentes da amostra, o giro de estoque está contido no ponto de pedido.

O indicador de uso de fontes de financiamento externo foi deletado, porque a amostra se compõe de MPEs e estas sofrem de restrições financeiras e são discriminadas quanto ao acesso ao crédito bancário em economias emergentes (Love, Preve, \& Sarria-Allende, 2007), tornando-o pouco atrativo em razão dos altos CT's e de agência de dívidas; consequentemente, o crédito comercial passa a ser a principal fonte de recursos externos.

O item orçamento de caixa não foi reconhecido pelos dirigentes das MPEs da amostra como instrumento de gestão financeira significativo. Possivelmente, os dirigentes têm conhecimentos gerenciais limitados (Michaelas, Chittenden, \& Poutziouris, 1998) sobre a utilidade desse instrumento de gestão, e, como o crédito comercial ativo e passivo é o principal destino e fonte de recursos financeiros, as condições de prazos de pagamento e de recebimento; junto com descontos, passaram a compor a variável latente gestão de caixa.

Após reespecificação do modelo com oito indicadores, os resultados apontam que o ajuste mínimo de discrepância na matriz de covariância da amostra com a matriz de covariância implícita do modelo foi alcançado $\left(\chi^{2}=30,8 ; \mathrm{DF}=23 ; \mathrm{p}<0,001\right)$, sugerindo, com isso, que a solução baseada no modelo de mensuração é plausível. Os graus de liberdade apontam que o modelo é superidentificado (Hair et $a l ., 2005)$, assegurando uma solução ótima de ajuste dos dados da amostra ao modelo reespecificado.

As estimativas de correlação entre fatores são de valores moderados, variando entre 0,43 e 0,64 , sugerindo a existência de validade discriminante das variáveis latentes na formação do construto. Da mesma maneira, e após a reespecificação do modelo inicial, as cargas estimadas dos itens preditores da escala nas variáveis latentes foram de valores significantes em nível de $\mathrm{p}$ valor $<0,001$, evidenciando a validade convergente da escala utilizada na medição dos fatores latentes. $\mathrm{O}$ alfa de Cronbach foi de 0,85 , 
indicando o grau de confiabilidade da escala em medir diferenças entre respondentes e entre as variáveis latentes (ANOVA: $\mathrm{F}=14,10 ; 0,000)$.

A variância explicada pela solução fatorial foi de 75,90\%, com comunalidade mínima de 0,67 e máxima de 0,82. Os índices de ajuste $\mathrm{KMO}=0,84$ e de esfericidade de Bartlett $=1570,84(\mathrm{DF}=28$; 0,000 ) foram significativos a $0,1 \%$, indicando uma boa adequação de possibilidade de tratamento dos dados com a análise fatorial.

A confiabilidade composta (CC) é uma medida de consistência interna dos indicadores de cada construto e descreve o grau em que eles indicam o mesmo fator latente. Conforme Hair, Anderson, Tatham e Black (2005), valores acima de 0,70 são aceitáveis e, abaixo destes, podem sê-lo, se o estudo for exploratório. Neste estudo, os resultados, como apresentados na Tabela 4, a seguir, sugerem que os indicadores usados para medir as dimensões de gestão de oferta de crédito e de controle de caixa são mais consistentes que os indicadores usados para medir o componente latente de gestão de estoques.

Tabela 4

\section{Confiabilidade Composta e Variância Explicada}

\begin{tabular}{llll}
\hline & Gestão de crédito & Gestão de caixa & Gestão de estoque \\
\hline CC & 0,88 & 0,74 & 0,55 \\
Variância explicada (\%) & 71,28 & 49,74 & 37,52 \\
\hline
\end{tabular}

Nota. Esta tabela mostra as medidas complementares de confiabilidade da escala por subdimensão do construto de gestão do capital de giro. Fonte: Elaborada pelo autor.

A variância média extraída revela a quantidade de variância nos indicadores explicada pela variável latente. Valores maiores estimados (> 50\%) desse parâmetro indicam que os indicadores são verdadeiramente representativos do construto latente. Coerente com os resultados da $\mathrm{CC}$, os indicadores do construto latente de gestão de estoque parecem ter pouca representatividade para explicá-lo $(<50 \%)$, quando comparados aos indicadores dos fatores de gestão de crédito e de controle de caixa. Ou seja, aproximadamente, $62,5 \%(100 \%$ - 37,52\%) da variância dos indicadores nível de investimento em estoque e ponto de pedido não são explicados pelo fator latente de gestão de estoque. É possível que outros aspectos de gestão não contemplados neste estudo expliquem essa variação.

Portanto, com base nos índices de ajustes, não há suporte para rejeitar as hipóteses nulas da parte de mensuração do modelo, o qual será usado como base para testar as proposições com regressão estrutural. Como apontada na Tabela 5 a seguir, a análise conjunta dos índices evidencia que o modelo teórico proposto tem ajuste razoável aos dados da amostra do presente estudo.

Tabela 5

\section{Principais Índices de Ajuste}

\begin{tabular}{ccccc}
\hline Índices de ajuste & MM1FAT & MM2FAT & MM3FAT-BASE & MM3RE \\
CMIN $\left(\chi^{2}\right)$ & $451,33(\mathrm{DF}=44)$ & $319,3(\mathrm{DF}=43)$ & $262,24(\mathrm{DF}=41)$ & $2,42(\mathrm{DF}=13)$ \\
& $(0,000)$ & $(0,000)$ & $(0,000)$ & $(0,049)$ \\
NFI (PNFI) & $0,75(0,60)$ & $0,82(0,64)$ & $0,85(0,64)$ & $0,99(0,46)$ \\
CFI (PCFI) & $0,77(0,62)$ & $0,84(0,66)$ & $0,87(0,65)$ & $0,99(0,46)$ \\
\hline RMSEA & 0,15 & 0,12 & 0,11 & 0,04 \\
\hline
\end{tabular}

Nota. Fonte: Elaborada pelo autor. 
A suposição de erros de mensuração não correlacionados foi relaxada, e alguns erros de medição de indicadores, como, por exemplo, ponto de pedido e giro de estoques, foram permitidos covariarem nos modelos reespecificados, pois apresentavam, com base na literatura de suporte, raciocínios teórico e empírico substantivos.

\section{Equações estruturais}

A Figura 3, a seguir, exibe o diagrama de caminhos entre indicadores e construtos, as cargas fatoriais e as estimativas dos coeficientes de regressão.

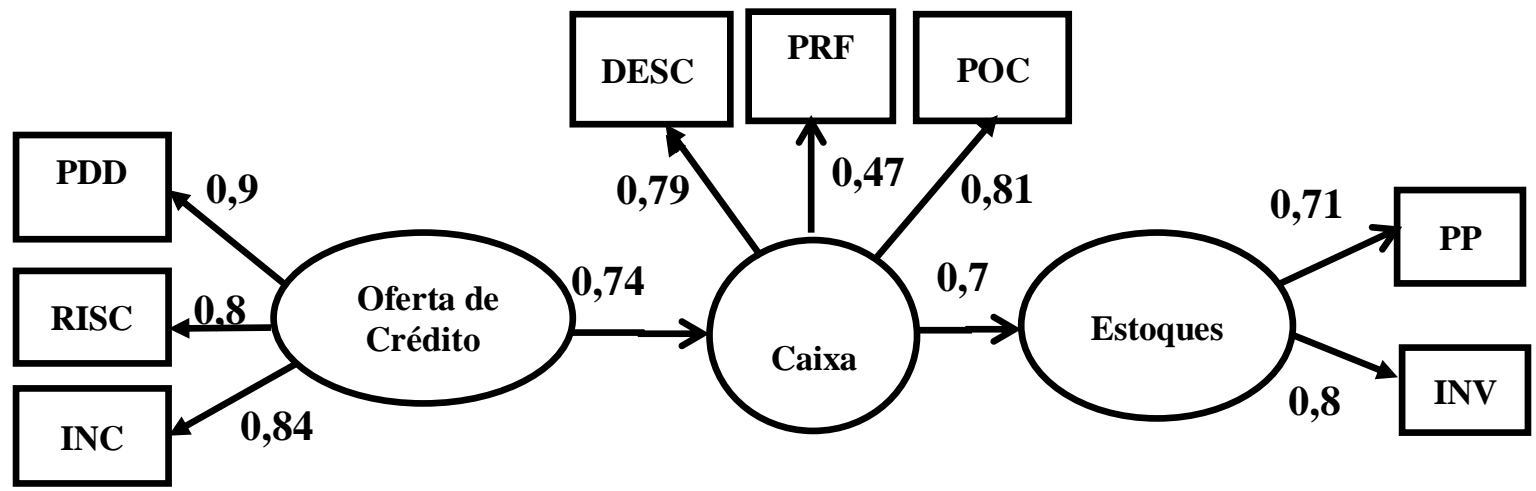

Figura 3. Estimativas de Coeficientes de Regressão Observados no Sistema de Equações Estruturais Fonte: Elaborada pelo autor.

A Tabela 6 mostra os resultados dos coeficientes padronizados de caminhos da regressão estrutural para os dois modelos de relacionamento. As variáveis dependentes (endógenas) são os fatores de gestão de caixa e o de estoques. A variável mediadora no modelo um é a gestão de caixa e, no dois, é a gestão de crédito.

Tabela 6

Sumário dos Resultados dos Testes de Proposições

\begin{tabular}{|c|c|c|c|}
\hline Modelo $1(\mathrm{CX})$ & Coeficientes & Modelo 2 (CRED) & Coeficientes \\
\hline H1: CX $\leftarrow$ CRED & $\mathbf{0 , 7 4 ^ { * * * }}$ & H1: CRED $\leftarrow \mathbf{C X}$ & $\mathbf{0 , 5 7 ^ { * * * * }}$ \\
\hline H2: EST $\leftarrow \mathbf{C X}$ & $\mathbf{0 , 7 0 * * *}$ & H2: EST $\leftarrow$ CRED & $\mathbf{0 , 2 3}$ \\
\hline INC $\leftarrow$ CRED & $0,84^{* * * * *}$ & $\mathrm{PRF} \leftarrow \mathrm{CX}$ & $0,46^{* * * *}$ \\
\hline $\mathrm{RISCO} \leftarrow \mathrm{CRED}$ & $0,80^{* * * *}$ & $\mathrm{POC} \leftarrow \mathrm{CX}$ & $0,88^{* * * *}$ \\
\hline $\mathrm{PRF} \leftarrow \mathrm{CX}$ & $0,47^{* * * *}$ & $\mathrm{DESC} \leftarrow \mathrm{CX}$ & $0,70^{* * * *}$ \\
\hline $\mathrm{POC} \leftarrow \mathrm{CX}$ & $0,81^{* * *}$ & $\mathrm{INC} \leftarrow \mathrm{CRED}$ & $0,87^{* * * *}$ \\
\hline $\mathrm{DESC} \leftarrow \mathrm{CX}$ & $0,78^{* * *}$ & $\mathrm{PDD} \leftarrow \mathrm{CRED}$ & $0,87^{* * * *}$ \\
\hline $\mathrm{PP} \leftarrow \mathrm{EST}$ & $0,71^{* * *}$ & RISCO $\leftarrow$ CRED & $0,79^{* * * *}$ \\
\hline NIVEL $\leftarrow$ EST & $0,79^{* * * *}$ & $\mathrm{PP} \leftarrow \mathrm{EST}$ & $0,71^{* * * *}$ \\
\hline $\mathrm{PDD} \leftarrow \mathrm{CRED}$ & $0,89^{* * * *}$ & NIVEL $\leftarrow$ EST & $0,78^{* * * *}$ \\
\hline p-valor & $1,5 \%$ & & $5 \%$ \\
\hline Hipóteses & Ambas suportadas & & $\begin{array}{c}\text { H1: Suportada } \\
\text { H2: Não suportada }\end{array}$ \\
\hline
\end{tabular}

Nota. Fonte: Elaborada pelo autor.

O símbolo ${ }^{* * *}$ indica significância a $1,5 \%$ no modelo um e de $5 \%$ no modelo dois 
As evidências empíricas suportam as hipóteses e sugerem que a geração de caixa interno das operações das empresas da amostra desempenhe um papel mediador positivo e significante (p-valor < $1,5 \%$ ), entre a variável antecedente gestão de oferta de crédito e gestão de estoque nas MPEs. Esse resultado está em linha com a teoria de Trade-off de custo de transações versus benefício de vendas incrementais e corroboram os achados por Frank e Goyal (2003) para as pequenas empresas, exatamente onde a TPO da hierarquia de fontes de financiamento (Myers, 1984) deveria prevalecer, devido às acentuadas assimetrias informacionais. Além do mais, reforça a importância da oferta de crédito como uma estratégia empresarial relevante para as MPEs financiarem seus clientes, por meio de recebíveis, enquanto são, simultaneamente, financiadas pelos fornecedores.

Para dirigentes dessas MPEs, a sincronização entre prazos médios de recebimento e de pagamento e a adoção de política de oferta de descontos são relevantes para se garantir a liquidez das firmas contra eventuais choques monetários e de demanda, e esse modelo pode ser utilizado em trabalhos futuros, como proxy para a gestão de caixa. Em contraste, a gestão de oferta de crédito não se mostrou uma mediadora significativa quando a gestão de caixa foi considerada variável exógena da gestão de estoques. Assim, a hipótese H2 (relação direta entre gestão de caixa e de estoques) não foi suportada.

Os resultados complementares das cargas de caminhos entre variáveis indicadoras e latentes fornecem informações importantes para gestores e stakeholders. Por exemplo, a carga de caminho entre $\mathrm{PRF} \leftarrow \mathrm{CX}(0,47)$ é a de menor valor, significando que as firmas têm alta propensão a atrasar pagamentos a fornecedores. Entretanto, em decorrência da confiança do relacionamento comercial frequente e de investimento específicos de longo prazo, são comuns as renegociações de débito.

\section{Conclusões}

O objetivo deste artigo foi investigar os relacionamentos entre as variáveis latentes que formam o construto de gestão do capital de giro em MPEs no Brasil. Para isso, utilizou-se uma escala, desenvolvida e aplicada por Howorth e Westhead (2003) no Reino Unido, de indicadores de práticas de gestão de capital de giro. Foram identificados quatro tipos de empresa, quanto ao foco de gestão: em crédito, em caixa, em estoques, e aquelas sem foco definido. Porém, evidências sobre o relacionamento entre essas variáveis latentes não figuram na literatura.

A análise fatorial confirmatória e exploratória evidencia a formação de três variáveis latentes para os resultados empíricos brasileiros, porém com cargas em fatores diferentes dos encontrados no Reino Unido. Esses resultados sugerem que dirigentes de MPEs em economias emergentes, e ainda com acentuadas imperfeições de mercado, percebem essas variáveis de maneira diferente, o que afeta a política financeira que adotam na gestão do negócio. Os indicadores de giro de estoques, financiamento externo e orçamento de caixa não foram significativos como variáveis dos fatores latentes de gestão de estoques e de caixa.

Na percepção de alguns dirigentes entrevistados, a rotina ponto de pedido foi um indicador que emergiu como relevante, pois, ao conhecê-lo, o giro já foi considerado na informação e não o contrário. Isso pode ser em razão da falta de clareza entre os dois conceitos e da baixa formação gerencial dos dirigentes.

A exclusão de financiamento externo deve-se, possivelmente, à resistência dos dirigentes em operar com crédito bancário, pois lhes é restrito o acesso a recursos financeiros com a finalidade de financiar as necessidades de giro e de investimentos permanentes. Por isso, reconhecem, no crédito ao consumidor e comercial, ativo e passivo, e na geração de caixa interno, o seu porto seguro para a continuidade das operações.

Os resultados sinalizam que a sincronização de prazos de recebimento e de pagamentos com a adoção de políticas de desconto emergiu como indicador de gestão de caixa, essencial para assegurar a gestão da liquidez dessas firmas. 
A proposição de que a gestão das práticas de oferta de crédito determina a gestão de rotinas de estoques foi suportada com a gestão de geração de caixa interna, atuando como um construto mediador. Para dirigentes das MPEs brasileiras, a concessão de créditos a clientes atua direta e positivamente como antecedente das decisões de caixa. Desse modo, os gestores buscam conciliar a maturidade de prazos de contas a receber e a pagar, oriunda de créditos aos consumidores e comerciais (ofertados e recebidos) com desconto por antecipação de pagamentos ou por pagamentos à vista, como meio de garantir liquidez às firmas. Ao dimensionar esses prazos no fluxo de caixa, parecem usar essas informações para decidirem sobre a gestão de estoques.

O efeito direto de gestão de crédito sobre gestão de caixa foi positivo e significativo a 1,5\% no valor de 0,74 , e com efeito indireto sobre gestão de estoques de 0,52 . Essas estimativas podem ser úteis nas decisões inerentes aos componentes do capital de giro. Neste estudo, uma das limitações refere-se à localização geográfica das empresas da amostra, situadas em estados com os maiores índices de bancarização, escolarização e desenvolvimento econômico, e as outras são as ressalvas clássicas quanto à generalização dos resultados dos estudos que usam dados de coleta por conveniência e com base na percepção e opinião dos entrevistados sobre as suas práticas de gestão.

Em estudos futuros, seria interessante aplicar a escala em firmas de todos os estados no sentido de verificar o comportamento dos dirigentes brasileiros sobre as questões de gestão de capital de giro. As firmas não listadas em bolsa, tanto de médio como de grande porte, podem ser outra frente de investigação.

\section{Referências}

Akerlof, G. A. (1970). The market for "lemons": quality uncertainty and the market mechanism. The Quarterly Journal of Economics, 84(3), 488-500. doi: 10.2307/1879431

Baker, H. K., Singleton, J. C., \& Veit, E. T. (2011). Survey research in corporate finance: bridging the gap between theory and practice (Financial Management Association Survey and Synthesis Series). New York: Oxford University Press.

Balbinotti, M. A. A., Benetti, C., \& Terra, P. R. S. (2006). Translation and validation of the GrahamHarvey survey for the Brazilian context. International Journal of Managerial Finance, 3(1), 2648. doi: 10.1590/S0103-166X2011000200013

Bates, T. W., Kahle, K. M., \& Stulz, R. M. (2009). Why do U. S. firms hold so much more cash than they used to? Journal of Finance, 64(5), 1985-2021. doi: 10.1111/j.1540-6261.2009.01492.x

Baum, C. F., Schafer, D., \& Talavera, O. (2011). The impact of the financial system's structure on firm's financial constraints. Journal of International Money and Finance, 30(4), 678-691. doi: 10.1016/j.jimonfin.2011.02.004

Berle, A., \& Means, G. (1932). The modern corporation and private property. New York: Macmillan.

Bloom, N., \& Van Reenen, J. (2010). Why do management practices differ across firms and countries? Journal of Economic Perspectives, 24(1), 203-224. doi: 10.1257/jep.24.1.203

Brigham, E. F., \& Ehrhardt, M. C. (2007). Administração financeira - Teoria e prática (10a ed.). Thomson: São Paulo.

Byrne, B. M. (2001). Structural equation modeling with AMOS: basic concepts, applications and programming. Mahwah, New Jersey: Lawrence Erlbaum Associates.

Caouette, J. B., Altman, E., \& Narayanan, P. (2009). Gestão do risco de crédito: o grande desafio dos mercados financeiros globais. Rio de Janeiro: Qualitymark. 
Carvalho, C. J. de, \& Schiozer, R. F. (2012). Gestão de capital de giro: um estudo comparativo entre práticas de empresas brasileiras e britânicas. Revista de Administração Contemporânea, 16(4), 518-543. Recuperado de http://www.spell.org.br/documentos/ver/7490/gestao-de-capital-degiro--um-estudo-comparativo-entre-praticas-de-empresas-brasileiras-e-britanicas-/i/pt-br. doi: $10.1590 / \mathrm{S} 1415-65552012000400003$

Chang, C.-H., Dandapani, K., \& Prakash, A. J. (1995). Current assets policies of European corporations: a critical examination [Special Issue]. Management and International Review. Journal of International Business, 2, 105-117. doi: 10.1007/978-3-322-90985-5_8

Chang, C., Lee, A. C., \& Lee, C. F. (2009). Determinants of capital structure choice: a structural equation modeling approach. The Quarterly Review of Economics and Finance, 49(2), 197-213. doi: 10.1016/j.qref.2008.03.004

Coase, R. (1937). The nature of the firm. Economica, 4(16), 386-405. doi: 10.1111/j.14680335.1937.tb00002.x

Faulkender, M., \& Wang, R. (2006). Corporate financial policy and the value of cash. Journal of Finance, 61(4), 1957-1990. doi: 10.1111/j.1540-6261.2006.00894.x

Frank, M., \& Goyal, V. K. (2003). Testing the pecking order theory of capital structure. Journal of Financial Economics, 67(2), 217-248. doi: 10.1016/S0304-405X(02)00252-0

García-Teruel, P. J., \& Martínez-Solano, P. M. (2007). Effects of working capital management on SME profitability. International Journal of Managerial Finance, 3(2), 164-177. doi: $10.1108 / 17439130710738718$

García-Teruel, P. J., \& Martínez-Solano, P. M. (2010). Determinants of trade credit: a comparative study of European SMEs. International Small Business Journal, 28(3), 215-233. doi: $10.1177 / 0266242609360603$

Gitman, L. J. (2010). Princípios de administração financeira (12a ed.). São Paulo: Pearson.

Hair, J. F., Jr., Anderson, R. E., Tatham, R. L., \& Black, W. C. (2005). Análise multivariada de dados (5a ed.). Porto Alegre: Bookman.

Hill, M. D., Kelly, G. W., \& Highfield, M. J. (2010). Net operating working capital behavior: a first look. Financial Management, 39(2), 783-805. doi: 10.1111/j.1755-053X.2010.01092.x

Howorth, C., \& Westhead, P. (2003). The focus of working capital management in UK small firms. Management Accounting Research, 14(2), 94-111. doi: 10.1016/S1044- 5005(03)00022-2

Islam, S. S., \& Mozumdar, A. (2007). Financial market development and the importance of internal cash: evidence from international data. Journal of Banking and Finance, 31(3), 641-659. doi: 10.1016/j.jbankfin.2006.06.009

Jensen, M. C., \& Meckling, W. C. (1976). Theory of the firm: managerial behaviour, agency costs and ownership structure. Journal of Financial Economics, 3(4), 305-360. doi: 10.1016/0304405X(76)90026-X

Kieschnick, R. L., Laplante, M., \& Moussawi, R. (2012). Working capital management and shareholder wealth [Working Paper $n^{\circ}$ 1431165]. Social Science Research Network, Rochester, NY, USA. Recuperado de http://papers.ssrn.com/sol3/papers.cfm?abstract_id=1431165

Klem, L. (1995). Path analysis. In L. G. Grimm \& P. R. Yarnold (Eds.), Reading and understanding multivariate statistics (pp. 65 -98). Washington, DC: American Psychological Association. 
Lamont, O. (1997). Cash flow and investment: evidence from internal capital markets. The Journal of Finance, 52(1), 83-109. doi: 10.1111/j.1540-6261.1997.tb03809.x

Ling, D. C., Naranjo, A., \& Nimalendran, M. (2000). Estimating returns on commercial real estate: a new methodology using latent variable models. Real Estate Economics, 28(2), 205-231. doi: $10.1111 / 1540-6229.00799$

Love, I., Preve, L. A., \& Sarria-Allende, V. (2007). Trade credit and trade banking: evidence from recent financial crises. Journal of Financial Economics, 83(2), 453-469. doi:10.1016/j.jfineco.2005.11.002

Maddala, G. S., \& Nimalendran, M. (1995). An unobservable component panel data model to study the effects of earnings surprises on stock prices, trading and bid-ask spreads. Journal of Econometrics, 68(1), 229-242. doi: 10.1016/0304-4076(94)01650-O

Michaelas, N., Chittenden, F., \& Poutziouris, P. (1998). A model of structure capital decision making small firms. Journal of Small Business and Enterprises Development, 5(3), 246-260. doi: 10.1108/EUM0000000006786

Myers, S. C. (1984). The capital structure puzzle. Journal of Finance, 39(3), 574-592. doi: $10.1111 / \mathrm{j} .1540-6261.1984 . t b 03646 . x$

Myers, S. C., \& Majluf, N. (1984). Corporate financing and investment decisions when firms have information that investors do not have. Journal of Financial Economics, 13(2), 187- 221. doi: $10.3386 / \mathrm{w} 1396$

Opler, T., Pinkowitz, L., Stulz, R., \& Williamson, R. (1999). The determinants and implications of corporate cash holdings. Journal of Financial Economics, 52(1), 3-46. doi: 10.1016/S0304405X(99)00003-3

Örtqvist, D., Masli, E. K., Rahman, S. F., \& Selvarajah, C. T. (2006). Determinants of capital structure in new venture: evidence from Swedish longitudinal data. Journal of Development and Entrepreneurship, 11(4), 277-296. doi: 10.1142/S1084946706000477

Paul, S. Y., \& Boden, R. (2011). Size matters: the late payment problem. Journal of Small Business and Enterprise Development, 18(4), 732-747. doi: 10.1108/14626001111179776

Preve, L., \& Sarría-Allende, V. (2010). Working capital management. Oxford University Press: USA.

Ross, S. A. (1973). The economic theory of agency: the principal's problem. American Economic Review, 63(2), 134-139.

Ross, S. A., Westerfield, R., \& Jordan, B. (2000). Princípios de administração financeira (2a ed.). Atlas: São Paulo.

Shin, H., \& Soenen, L. (1998). Efficiency of working capital management and corporate profitability. Financial Practice and Education 8(2), 37-45.

Sicsú, A. L. (2010). Credit scoring. São Paulo: Edgar Blucher.

Taylor-Powell, E., \& Hermann, C. (2000). Collecting evaluation data: surveys. Madison, MI: University of Wisconsin Extension, Cooperative Extension. Recuperado de http://learningstore.uwex.edu/assets/pdfs/G3658-10.PDF

Titman, S., \& Wessels R. (1988). The determinants of capital structure choice. Journal of Finance, 43(1), 1-19. doi: 10.1111/j.1540-6261.1988.tb02585.x 
Yang, C.-C., Lee, C.-F., Gu, Y.-X., \& Lee, Y.-W. (2010). Co-determination of capital structure and stock returns - A LISREL approach: an empirical test of Taiwan stock markets. The Quarterly Review of Economics and Finance, 50(2), 222-233. doi: 10.1016/j.qref.2009.12.001

Yang, S. A., \& Birge, J. R. (2013). How inventory is (should be) financed: trade credit in supply chains with demand uncertainty and costs of financial distress [Working paper]. Social Science Research Network, Rochester, NY. Recuperado de http://papers.ssrn.com/sol3/papers.cfm?abstract_id=1734682

Weston, J. F., \& Brigham, E. P. (2000). Fundamentos de administração financeira (10a ed.). São Paulo: Makron Books.

Williamson, O. E. (1981). The economics of organization: the transaction cost approach. American Journal of Sociology, 87(3), 548-577.

\section{Dados do Autor}

Claudinê Jordão Carvalho

Av. Brasil, 3100, 38400-718, Uberlândia, MG, Brasil. E-mail: jordao@ufu.br 